\title{
La recepción del pensamiento de Freud en la obra de Ramón y Cajal
}

Jordi Rusiñol Estragués \& Virgili Ibarz Serrat

Universitat Ramon Llull

Barcelona - España

Si analizamos la trayectoria de estas dos grandes personalidades podemos apreciar unos intereses comunes. Los dos estudian medicina y se interesan por la fisiología del sistema nervioso. El hipnotismo y la sugestión causan una gran impresión en los dos científicos. El hipnotismo fue practicado por Freud a su vuelta a Viena y fue utilizado por Cajal con sus pacientes en Valencia. Cajal no acepta las interpretaciones freudianas de los sueños.

Además de las diferencias en el análisis de los sueños, la psicología freudiana y la cajaliana explican la vida mental de forma muy diferente.

pensamiento de Freud / Ramón y Cajal

\section{The reception of the thought of Freud in the work of Ramon y Cajal}

If we analyzed the trajectory of these two great personalities we can appreciate common interests. Both study medicine and they are interested in the physiology of the nervous system. Both, hypnotism and its suggestion cause a great impression in these two scientists. Freud practiced hypnotism during its return to Vienna and Cajal used it with his patients in Valencia. Cajal does not accept the Freudians interpretations of the dreams.

Besides the differences in the analysis of the dreams, the psychology of Freud and Cajal explain mental life in a very different ways. 
A la muerte de Cajal y de acuerdo con su voluntad, sus libros, manuscritos y correspondencia fueron trasladados al Instituto Cajal. Las circunstancias políticas de España, primero, y posteriormente la guerra civil, impidieron su conservación y desapareció casi todo. La biblioteca personal de Cajal se encuentra ahora dividida, siendo su poseedor, junto con los familiares, el Instituto Cajal.

De la biblioteca personal de Cajal se han podido conservar dos obras de Freud: Psicopatología de la vida cotidiana (Madrid, 1922, Biblioteca Nueva) y La interpretación de los sueños (Madrid, 1923, Biblioteca Nueva). Hemos comprobado que Cajal hace alusiones a Freud sin entusiasmo, pero con respeto no exento de cautela; en cambio, en los juicios expresados a las personas conocidas se muestra mucho más duro con la interpretación freudiana (Ibarz, 1994).

Para comprender la postura cajaliana debemos hacer una reflexión histórica. El siglo XIX, al que Freud y Cajal llegan, es especialmente rico para la psicología, que ve desarrollar multitud de aspectos que en ella confluyen. Desde la fisiología de los sentidos, que implica a las ciencias físicas: estudio de la luz y el sonido, entre otros, y el establecimiento de las leyes sensoriales de la percepción, hasta las metodologías conductistas y su recurso al muestreo y a la estadística matemática. Desde la neurología y su recurso a la electrici- dad y a la química, hasta el psicoanálisis, que nos muestra nuestros aspectos inconscientes.

Aparentemente antitéticas algunas de estas corrientes se separan y hasta se descalifican en nombre, generalmente, del positivismo científico, en boga en el siglo XIX; no siempre, por otra parte, coincidente en sus perspectivas. En este momento histórico se debaten grandes concepciones de hombres de la talla de Pavlov, Freud, James o Cajal, cada uno de los cuales quedará en la historia de la ciencia como un innovador sobre reflexología, psicoanálisis, funcionalismo americano y neurología en el caso de nuestro Cajal.

Todos estos científicos parten de una singular inquietud por el desentrañamiento de los problemas psicológicos. Debido a las grandes perspectivas llegan a consecuencias diversas y hasta aparentemente -debido a la especialización de sus métodos- incompatibles. Pavlov se acantonará en el estudio de la fisiología del reflejo condicionado, manteniendo posturas antiintrospeccionistas. Freud, comenzando como Cajal en la neurología, pasa al estudio del hipnotismo y a configurar la perspectiva de lo reprimido en el inconsciente. James, también desde la neurología, cambiará a la perspectiva funcionalista e incluso trascendentalista. Cajal permanecerá en el campo positivo de la histología del sistema nervioso. Sin embargo, estudiará muchos de los campos de la psicología de su tiempo, e 
incluso los fenómenos parapsicológicos, llamados en aquel momento psicología morbosa. Veremos cómo Cajal no acepta la teoría del inconsciente freudiano a pesar de manejar conceptos como la sugestión o utilizar la hipnosis en su trabajo.

Cajal publicó en 1908 Las teorías sobre el ensueño. Su contenido apareció en los números 14 y 15 de Cajal. Revista de Medicina y Cirugía de la Facultad de Medicina de Madrid. Estos artículos debían ser los primeros de una serie que, sin embargo, no tuvo continuación. Sabemos que dejó sin publicar un libro sobre el sueño, y los fenómenos del ensueño, cuyo manuscrito se perdió durante la guerra civil. Cajal sintió un gran interés sobre el sueño o el ensueño, como él dice. Debemos hacer notar que Cajal propuso a la Academia de la Lengua restringir el significado de la palabra sueño. Solicitaba que fuera suprimida la acepción de visión, alucinación, etc., y que éstas se concediesen exclusivamente a la palabra ensueño y sus derivados. Pensaba que de esta forma se terminaría la inferioridad del castellano con respecto a otras lenguas que distinguen los dos conceptos, y se evitarían confusiones.

Cajal anotaba regularmente el contenido de sus propios sueños y los de las personas que tenía alrededor, y estudió las principales teorías de interpretación. En sus escritos hace referencias a las observaciones contrarias a la interpretación freudiana. Creemos que sería interesante ver cómo interpretaba los sueños. Sin embargo, estos manuscritos se dan por perdidos.

Sólo se han podido conservar algunos de los sueños que escribía, como era frecuente en él, en trozos de cuartillas o en cualquier otro papel; son resúmenes rapidísimos; por ejemplo, entre los manuscritos del Instituto Cajal aparece "Sueño filológico": "Estoy entre amigos y me indigno sobre el verbo finanzar y gaspillar por despilfarrar" (Carpeta 18 del Museo Cajal).

En la misma carpeta se conservan dos sueños resumidos, sin fecha. Uno corresponde a un sueño de su criada:

Sueño de mi criada.

Que estaba llena de víboras de diversos tamaños que le corrían por debajo de la camisa; estaba aterrada y lloraba y que una prima le dijo: (que) desnúdese; ella no quería, pero las víboras fueron desfilando al quitarse la camisa, y (quedó) se despertó tan asustada y llorosa que ya no pudo dormir.

¿A qué atribuir esto? No lo sabe. No ha leído nada de víboras ni novela donde se hable de reptiles; es episodio amplificado y deformado de algún cuento de su niñez: en su pueblo hay víboras, aunque escasas (Escritos inéditos, p. 377).

Hemos visto que Cajal interpreta este sueño como una reminiscencia de la niñez. En otra cuartilla comenta el sueño de un hombre de 80 años sobre deseos sexuales hacia su mujer:

Sueño

Ochentón; mujer enferma de corazón y grave: importante. Sueña que enciende luz y está en el cuarto de su esposa dormida y sufriendo. Se acuerda de dos 
cosas, de la enfermedad de su mujer y de su absoluta impotencia. Eso le persuade de que debe retirarse. Se retira a su cuarto y despierta. ¿Deseo realizado? No; recuerdo revivido de actos realizados muchos años antes. ¿Qué deseo puede tener un hombre sin apetencia sexual, de glándulas atróficas? Efecto orgánico de hormonas tampoco, pues no existen, carece de deseos.

No hay escape. Es uno de tantos recuerdos de tiempos viejos; sus deseos son puramente cerebrales. Son ideas y nada más (Escritos inéditos, p. 377).

Hemos visto que el sueño de los deseos sexuales del hombre de 80 años lo explica como actos realizados muchos años antes. No admite otras interpretaciones.

Estudiando la correspondencia de Cajal, hemos encontrado una carta dirigida a los talleres de la imprenta de Casa Jacobo de Buenos Aires, el 19 de junio de 1933, año anterior a su muerte. Dice:

Me encanta la interpretación a que usted se lanza sobre las mentiras colectivas. En sus estudios, por desgracia, hay un gran fondo de verdad. Yo, que tengo en el telar un libro sobre la "Sugestión religiosa, política, médica, etc.”, todavía voy más lejos que usted, pues estimo como mentiras colectivas el psicoanálisis y la teoría de los ensueños de Freud. Casi todos los hechos del sabio vienés pueden explicarse por la sugestión individual y colectiva. De esto hablaré si consigo vivir lo bastante para redactar otro libro "Sobre el ensueño", donde resumo miles de autoobservaciones contrarias a las teorías de Freud (Cajal, 1933: p. 272).

Nosotros creemos que la perspectiva cajaliana es diametralmente opuesta a la freudiana. Para Cajal, lo no consciente, lo no dominado por la voluntad del yo, es una negatividad que no quiere asumir y, por esta razón, no quiere aceptar el inconsciente freudiano inquietante y dominador del yo.

No obstante, siguiendo la obra cajaliana observamos que en 1922, tras desvelar que el sueño es una actividad mental, admite la intervención de la imaginación creadora:

Pretendían los antiguos consolarnos de la muerte comparándola con el sueño, que suponían absolutamente inconsciente. Pero el sueño ha sido calumniado. Exceptuando quizá algunos momentos de inercia reparadora, el dormido sabe que lo está, espera despertar y contempla, con la cabalgata de sus recuerdos, más o menos deformados, la magia de la imaginación constructiva. Lejos, pues, de implicar reposo absoluto, el sueño nos proporciona actividad libre, desbordante así de los cauces del tiempo y del espacio como de los carriles de la lógica. Y si hubiéramos de tomar en serio las teorías famosas de Freud, el ensueño aportaría además la dicha suprema de ver realizadas las más acariciadas y gratas aspiraciones (Cajal, 1922: pp. 82-83).

Podemos observar que en las teorías cajalianas hay que desconfiar de toda idea que no provenga de nuestra razón consciente. Por esta razón, el inconsciente queda descalificado como objeto de estudio, y el psicoanálisis como ciencia. Desde el punto de vista positivista de Cajal será una especie de metafísica o de mística. En 1934, año de su muerte, cuando está analizando la memoria, expone que: 
Ni en el sueño nos abandona. Con ayuda de la fantasía creadora, reaviva en las tinieblas de lo subconsciente imágenes borrosas, próximas a extinguirse, proyectándolas a menudo en las incoherencias y fulgurantes alucinaciones del ensueño, que, pese a Freud y algunos autores impregnados de misticismo, escapa a toda explicación racional (Cajal, 1934: p. 45).

Para Cajal, el sueño queda descrito, en su aspecto fisiológico, como una descarga de los centros corticales no utilizados durante las horas de vigilia. Piensa que las imágenes simbólicas de los sueños se producen por el miedo a la muerte de las ideas inactivas. Por este motivo, soñamos con frecuencia escenas de la niñez o juventud raras veces recordadas. También soñamos imágenes caprichosas y absurdamente combinadas que no entraron en el campo de la conciencia. Estas imágenes se producen por un mecanismo compensatorio. Durante el sueño no participan los centros que más han trabajado en la vigilia, es decir, los encargados de las síntesis de imágenes, así como los dedicados a la actividad crítica. En cambio, sí lo hacen los que han permanecido inactivos durante la vigilia. Por esta razón, según Cajal, durante el sueño trabajan las células cerebrales donde están grabadas las imágenes inconscientes. Podemos advertir que Cajal considera que el inconsciente es una reserva de imágenes.

No obstante, podemos observar que la crítica cajaliana no es menos dura cuando hace una autocrítica de sus teorías.
En la carta dirigida a Zacarías MartínezNúñez, sin fecha, le comunica:

No le interese a usted demasiado lo que los histólogos imaginan para dar del sueño una explicación físico-química o histo-fisiológica. En realidad, nada se sabe de seguro sobre el tema; por eso, yo mismo, comprendiendo que está verde, he retirado de la circulación mi conjetura, y así no la cito siquiera en mi obra de los centros nerviosos. Claro que esta hipótesis vale lo que la otra: muy poco (Escritos inéditos, p. 219).

Hemos visto que Cajal no acepta la existencia de una parte inconsciente de la personalidad. Creemos que contempla al hombre ideal, es decir, al hombre dotado de libre albedrío, de conciencia y de voluntad soberana, y que no puede imaginarse al hombre con aspectos inconscientes. Nos llama la atención que rechace de forma tan tajante la interpretación freudiana. Y sin embargo, si observamos la cronología de los dos autores podemos apreciar cierto paralelismo. Los dos estudian medicina y se interesan por la fisiología del sistema nervioso. Posteriormente, ambos se interesan por la neurología, y, en 1885 , mientras Freud obtiene una beca para estudiar técnicas hipnóticas con Charcot en el Hospital de la Salpêtrière de París, Cajal crea un comité de investigaciones psicológicas en Valencia, siguiendo las orientaciones de Berheim de Nancy. El hipnotismo y la sugestión causan una gran impresión en ambos. El hipnotismo fue utilizado por Freud antes de crear el psicoanálisis y practicado con éxito por Cajal en el primer 
parto bajo sugestión hipnótica del que se conoce documentación en España.

Es interesante analizar las diferencias entre la explicación positivista y mecanicista cajaliana y la interpretación freudiana. Según Freud, existe una razón biológica de la religiosidad, y es la impotencia y la necesidad de protección en que nace el hombre. Siendo ya adulto, siente la nostalgia de los progenitores que le protegieron en la infancia $\mathrm{y}$ hace una regresión a sus primeras vivencias, sublimando a sus padres, que representan la idea de Dios. La interpretación freudiana se pone de manifiesto en Un recuerdo infantil de Leonardo de Vinci, donde Freud descubre una relación entre el complejo paternal y la creencia en Dios, relación que influirá en los escritos posteriores sobre religión; y en Totem y tabú, en que partiendo de la hipótesis darwiniana sobre el estado primitivo social de la humanidad, Freud expone que la comida totémica constituyó el punto de partida de las organizaciones sociales, de las restricciones morales y de la religión.

En cambio, para Cajal, el ambiente moral establece en el cerebro modos de asociación celular diferentes para cada niño. De estas formas de asociación dependerá el carácter, la personalidad y el sentimiento religioso de los adultos. Piensa que a los 75 o a los 80 años, las conversiones religiosas son imposibles porque el cerebro ha cristalizado en una estructura y una ideología invariables.

\section{REFERENCIAS}

Ibarz Serrat, V. (1994). La psicología en la obra de Santiago Ramón y Cajal. Zaragoza: Institución Fernando el Católico.

Ramón y Cajal, S. (1922). Charlas de café. Pensamientos, anécdotas y confidencias. Madrid: Imprenta Juan Pueyo/Espasa-Calpe.

Ramón y Cajal, S. (1933). Carta a Talleres Casa Jacobo. Madrid, 19 de junio. En: Escritos inéditos, p. 272.

Ramón y Cajal, S. (1934). El mundo visto a los ochenta años. Impresiones de un arteriosclerótico. Madrid: Tipografía Artística.

Ramón y Cajal, S. (1960). Escritos inéditos. En: Durán Muñoz, García \& Alonso Burón, Francisco (Comps.). Cajal. Vida y obra. Tomo 2. Zaragoza: Institución Fernando el Católico, C.S.I.C. 